\title{
Autotransfusão intra-operatória em cirurgia cardíaca: estudo comparativo de 140 casos
}

\author{
Sérgio Domingos VIEIRA *, Marielza dos SANTOS *, Thucydides ROSALES *, Luiz Carlos Bento de \\ SOUZA *, Jarbas J. DINKHUYSEN *, Paulo CHACCUR *, Camilo ABDULMASSIH NETO, Ricardo \\ PAVANELLO *, Adib D. JATENE *
}

RBCCV 44205-192

\begin{abstract}
VIEIRA, S. D.; SANTOS, M.; ROSALES, T.; SOUZA, L. C. B.; DINKHUYSEN, J. J.; CHACCUR, P.; ABDULMASSIH NETO, C.; PAVANELLO, R.; JATENE, A. D. - Autotransfusão intra-operatória em cirurgia cardíaca: estudo comparativo de 140 casos. Rev. Bras. Cir. Cardiovasc., 7(4):287-292, 1992.

RESUMO: Utilizando-se programa dirigido para diminuição ou eliminaçāo do uso de sangue homólogo, em pacientes cirúrgicos graves, foi realizado um estudo comparativo entre 140 casos. Os pacientes foram divididos em 2 grupos de 70 casos cada, onde o Grupo A representava aqueles submetidos a cirurgia cardíaca com o uso de recuperadores celulares automatizados de sangue cell-saver, no Grupo B, os pacientes que nảo utilizaram cell-saver durante o ato cirúrgico (Grupo controle). A maioria era de reoperaçōes: $71,1 \%$ no Grupo A e $74,2 \%$ no Grupo B, observando-se, ainda, semelhança entre os respectivos grupos em relação a: idade, distribuição por sexo, tipo de operaçāo, condiçōes clínicas e aspectos laboratoriais pré-operatórios (coagulograma; eritrograma; série bioquímica). No Grupo A a utilizaçāo média de sangue homólogo, durante o ato cirúrgico, foi de $628 \mathrm{ml}$, e $479 \mathrm{ml}$ no pós-operatório imediato. Já no Grupo B o uso de sangue homólogo foi de $1.271 \mathrm{ml}$ e $1.095 \mathrm{ml}$, respectivamente. A perda sangūínea média na sala cirúrgica do Grupo $A$ foi de $380 \mathrm{ml}$, enquanto que a do Grupo B foi de $899 \mathrm{ml}$. O número de pacientes do Grupo A que não necessitou de sangue homólogo durante o período de internação foi o dobro $(5,7 \%)$ em relação ao Grupo $B(2,8 \%)$. A maioria dos pacientes do Grupo $A(51,4 \%)$ utilizou no máximo 2 unidades de sangue homólogo, enquanto que a maioria dos paciientes do Grupo B $(78,6 \%)$ utilizou entre 3 ou mais de 5 unidades de sangue homólogo. $O$ estudo mostra, portanto, que a utilização da autotransfusāo intra-operatória (ATI) através de processadores celulares automatizados (cell-saver) em cirurgia cardíaca é um procedimento seguroe eficaz, reduzindoem aproximadamente $50 \%$ a utilizaçäo de sangue homólogo, com as possíveis reaçōes transfusionais e, principalmente, o risco da transmissão de doenças infecto-contagiosas.
\end{abstract}

DESCRITORES: sangue, autotransfusāo, cirurgia cardíaca.

\section{INTRODUÇĀO}

A autotransfusāo nāo é uma concepção nova. O crescente aumento do número de cirurgias cardíacas e conseqüentemente a maior demanda para os bancos de sangue ${ }^{15}$, associado, principalmente, com o receio da transmissão de doenças infectocontagiosas (AIDS) por transfusão sangüínea ${ }^{3}$ foram fatores determinantes para o desenvolvimento de programas visando à diminuição do uso de sangue homólogo ${ }^{1.5}$. Atualmente sâo utilizados os seguintes métodos: doação pré-operatória ${ }^{12}$; recuperação intra-operatória ${ }^{4}$, hemodiluição normovolêmica aguda " $\mathrm{e}$ recuperação pós-operatória ${ }^{8}$. Essas técnicas têm sido aplicadas em diferentes grupos de pacientes, tanto isoladas como combinadas entre si, e os grupos estudados muitas vezes não têm sido devidamente comparados.

Trabalho realizado no Hospital do Coração da Associação do Sanatório Sírio. São Paulo, SP, Brasil.

Apresentado ao $19^{\circ}$ Congresso Nacional de Cirurgia Cardíaca. São Paulo, SP, 7 a 9 de maio, 1992.

* Do Hospital do Coração.

Endereço para separatas: Sérgio Domingos Vieira, Rua Desembargador Eliseu Guilherme, 123. 04004 Sâo Paulo, SP, Brasil. 
VIEIRA, S. D.; SANTOS, M.; ROSALES, T.; SOUZA, L. C. B.; DINKHUYSEN, J. J.; CHACCUR, P.; ABDULMASSIH NETO, C.; PAVANELLO, R.; JATENE, A. D. - Autotransfusão intra-operatória em cirurgia cardíaca: estudo comparativo de 140 casos. Rev. Bras. Cir. Cardiovasc., 7(4):287-292, 1992.

No presente estudo, grupos homogêneos de pacientes foram selecionados para avaliar a eficácia da autotransfusāo intra-operatória na diminuiçāo da utilizaçāo de sangue homólogo e a sua teórica desvantagem na indução de coagulopatias pela remoçāo dos fatores de coagulação no processo de lavagem celular, o qual poderia levar a um aumento da hemorragia em operaçōes cardíacas ${ }^{14}$.

\section{CASUÍSTICA E MÉTODOS}

Foi realizando estudo comparativo entre 140 pacientes submetidos a cirurgia cardíaca, divididos em 2 grupos de 70 casos cada:

Grupo A: pacientes submetidos a autotransfusão intra-operatória com uso de recuperadores celulares automatizados (cell-saver), no período de abril/91 a outubro/91

Grupo B: pacientes que não utilizaram cellsaver durante o ato cirúrgico (Grupo controle), no período de novembro/88 a dezembro/91.

Todos os pacientes estudados apresentavam alto risco cirúrgico hemorrágico pré-operatório, tais como: reoperaçōes, dissecçōes da aorta, alteraçāo dos fatores de coagulaçāo e agregaçāo plaquetária 2. A idade média e a distribuição por sexo foram semelhantes em ambos os grupos (Tabela 1).

TABELA 1

COMPARAÇĀO REFERENTE Ȧ IDADE, EXPRESSA EM ANOS, E DISTRIBUIÇĀO POR SEXO

\begin{tabular}{|c|c|c|c|c|c|}
\hline \multirow[t]{2}{*}{ GRUPOS } & \multicolumn{3}{|c|}{ IDADE } & \multicolumn{2}{|c|}{ SEXO } \\
\hline & $\bar{M}$ & MIN. & MAX. & MASC. & FEM. \\
\hline $\begin{array}{l}\text { Grupo A } \\
\text { (Cell-Saver) }\end{array}$ & 57,9 & 08 & 85 & $78,5 \%$ & $21,5 \%$ \\
\hline $\begin{array}{l}\text { Grupo B } \\
\text { (Controle) }\end{array}$ & 58,0 & 20 & 73 & $71,4 \%$ & $28,6 \%$ \\
\hline
\end{tabular}

$\overline{\mathrm{M}}:$ Média

Houve grande maioria das reoperaçōes, sendo que, no Grupo A foram $54(77,1 \%)$ casos de reoperação e no Grupo B foram $52(74,2 \%)$. A revascularizaçāo do miocárdio foi a operaçāo mais freqüente, seguida das valvares e dos aneurismas da aorta, conforme demonstra a Tabela 2 .

Nos pacientes submetidos a ATI com hematócrito acima de $40 \%$ e, principalmente, em condiçōes hemodinamicamente estáveis foi feita a coleta pré-operatória de uma unidade de sangue autólogo na sala cirúrgica, com o paciente anestesiado e devidamente monitorizada (21 pacientes: $30 \%$ ). Esse sangue foi reinfundido após a neutralização da heparina pelo sulfato de protamina. O controle da heparinização dos pacientes na sala cirúrgica foi realizado através do T.C.A. (tempo de coagulação ativada). Foram avaliados os exames pré-operatórios: coagulograma, contagem de plaquetas, série bioquímica, hematócrito e hemoglobina, realizados em cada paciente.

A cell-saver utilizada foi exclusivamente a Autotrans-Stat da Dideco/Shiley, Mirandola, Itália. Anticoagulação do sangue aspirado do campo cirúrgico foi feita utilizando-se soluçāo salina a $0,9 \%$ $(1.000 \mathrm{ml})$, com 25.000 unidades de heparina. A pressāo de aspiraçāo manteve-se entre $80-100$ $\mathrm{mmHg}$, ideal para se evitar hemólise celular. No reservatório de cardiotomia, o sangue é filtrado (49 $\mu \mathrm{m}$ ) e enviado ao bowl com capacidade de $225 \mathrm{ml}$, e velocidade de $5.600 \mathrm{rpm}$. O sobrenadante das células é coletado através da bolsa de desprezo e a lavagem dos glóbulos vermelhos é feita com 1.000 $\mathrm{ml}$ de solução fisiológica a $0,9 \%$ na técnica de $B Q W$ (melhor qualidade de lavagem). Nos casos onde houve CEC foi processado o conteúdo restante do oxigenador, após o término da mesma ${ }^{6}$. Os concentrados de glóbulos lavados possuem hematócrito de $60 \%$, sendo enviados à bolsa de reinfusão e administrados ao paciente no intra-operatório ou nas primeiras horas de UTI.

TABELA 2

TIPOS DE CIRURGIA, NÚMERO DE CASOS E PORCENTAGEM

\begin{tabular}{|c|c|c|}
\hline TIPOS DE CIRURGIA & $A T I$ & GC \\
\hline \multicolumn{3}{|l|}{ Revascularização } \\
\hline do miocárdio & $38(54,3 \%)$ & $45(64,27 \%)$ \\
\hline $1^{\text {a }}$ Cirurgia & $03(04,2 \%)$ & $04(05,6 \%)$ \\
\hline $2^{2}$ Cirurgia & $27(38,5 \%)$ & $41(58,6 \%)$ \\
\hline $3^{a}$ Cirurgia & $02(02,8 \%)$ & - \\
\hline \multicolumn{3}{|l|}{ Associaçōes } \\
\hline Aneurismec. VE & $04(05,7 \%)$ & - \\
\hline Comissurot. Valva Mitral & $01(01,4 \%)$ & - \\
\hline Retroca de Valva Mitral & $01(01,4 \%)$ & - \\
\hline Valvar & $18(25,7 \%)$ & $10(14,2 \%)$ \\
\hline $1^{\circ}$ Cirurgia & $04(04,7 \%)$ & $01(01,4 \%)$ \\
\hline $2^{3}$ Cirurgia & $07(10,0 \%)$ & $09(12,8 \%)$ \\
\hline $3^{2}$ Cirurgia & $05(07,1 \%)$ & - \\
\hline $4^{2}$ Cirurgia & $01(01,4 \%)$ & - \\
\hline $5^{a}$ Cirurgia & $01(01,4 \%)$ & - \\
\hline Aneurisma de aorta & $11(15,7 \%)$ & $15(21,4 \%)$ \\
\hline $1^{2}$ Cirurgia & $06(08,5 \%)$ & $13(18,5 \%)$ \\
\hline $2^{\circ}$ Cirurgia & $05(07,1 \%)$ & $02(02,8 \%)$ \\
\hline Cirurgia de Björk ( $3^{a}$ cirurgia) & $01(01,4 \%)$ & - \\
\hline Aneurismec. VE & $01(01,4 \%)$ & - \\
\hline \multicolumn{3}{|c|}{$\begin{array}{l}\text { Blalock modificado à direita + } \\
\text { plastia } \\
\text { Artéria pulmonar direita }\end{array}$} \\
\hline $\begin{array}{l}\text { Artéria pulmonar direita } \\
\qquad\left(4^{*} \text { cirurgia }\right)\end{array}$ & $01(01,4 \%)$ & - \\
\hline
\end{tabular}

ATI: Autotransfusāo intra-operatória; VE: ventrículo esquerdo; GC: Grupo de Controle. 
VIEIRA, S. D.; SANTOS, M.; ROSALES, T.; SOUZA, L. C. B.; DINKHUYSEN, J. J.; CHACCUR, P.; ABDULMASSIH NETO, C.; PAVANELLO, R.; JATENE, A. D. - Autotransfusão intra-operatória em cirurgia cardíaca: estudo comparativo de 140 casos. Rev. Bras. Cir. Cardiovasc., 7(4):287-292, 1992.

A técnica utilizada na perfusão dos pacientes foi padronizada e a anticoagulaçāo feita utilizandose heparina $(4-5 \mathrm{mg} / \mathrm{kg})$ e a sua neutralização através do sulfato de protamina, cuja dose variou de acordo com a volemia e a quantidade de heparina utilizada.

\section{RESULTADOS}

A recuperação média do Grupo A foi de $950 \mathrm{ml}$ de concentrado de glóbulos lavados, representando 2,10 unidades autólogas recuperadas por paciente (Tabela 3).

TABELA 3

RESULTADO DA RECUPERAÇĀO NA AUTOTRANSFUSĀO INTRA-OPERATÓRIA.

\begin{tabular}{|c|c|c|c|}
\hline & $\bar{M}$ & MIN. & MAX. \\
\hline $\begin{array}{l}\text { Volume aspirado } \\
\text { do campo }\end{array}$ & $513 \mathrm{ml}$ & $50 \mathrm{ml}$ & $4.473 \mathrm{ml}$ \\
\hline $\begin{array}{l}\text { Volume concentrado } \\
\text { autólogo }\end{array}$ & $950 \mathrm{ml}$ & $270 \mathrm{ml}$ & $3.051 \mathrm{ml}$ \\
\hline $\begin{array}{l}N^{2} \text { de unidades } \\
\text { recuperadas }\end{array}$ & 2,10 & 0,56 & 7,32 \\
\hline
\end{tabular}

$\overline{\mathrm{M}}$ : Média

A utilizaçāo média de sangue homólogo no Grupo A, durante o ato cirúrgico, foi de $628 \mathrm{ml}$ e de $479 \mathrm{ml}$ no pós-operatório imediato, sendo que no Grupo $B$ foi de $1.271 \mathrm{ml} \mathrm{e} 1.059 \mathrm{ml}$ o uso de sangue homólogo, respectivamente.

Em relação aos componentes e derivados (plasma, plaquetas, crioprecipitado) houve um discreto aumento no Grupo A em relação ao Grupo B no ato cirúrgico (Tabela 4).

A perda sangüínea média, na sala cirúrgica, no

TABELA 4

USO DE SANGUE/DERIVADOS NA CIRURGIA

\begin{tabular}{rll}
\hline & GRUPO A & GRUPO B \\
\hline Sangue Total (média) & $628 \mathrm{ml}$ & $1.271 \mathrm{ml}$ \\
Mínimo & zero & zero \\
Máximo & $4.500 \mathrm{ml}$ & $6.000 \mathrm{ml}$ \\
Plasma (média) & $224 \mathrm{ml}$ & $77 \mathrm{ml}$ \\
mínimo & $z e r o$ & zero \\
máximo & $1.000 \mathrm{ml}$ & $600 \mathrm{ml}$ \\
Plaquetas: Total & 58 unid. & 12 unid. \\
Crioprecipitado: Total & 42 unid. & 12 unid. \\
\hline
\end{tabular}

Grupo A, o qual utilizou a recuperação celular, foi de $380 \mathrm{ml}$, enquanto que no Grupo B foi de $899 \mathrm{ml}$.

Os níveis de hematócrito e de hemoglobina nos exames pré-operatórios e no $5^{\circ}$ dia do pós-operatório foram semelhantes em ambos os grupos, mas os pacientes do Grupo A apresentaram níveis significativamente maiores que no Grupo B no pósoperatório imediato, com conseqüente melhora nas condiçōes de recuperaçāo do paciente (Tabela 5).

TABELA 5

NIVEEIS DE HEMATÓCRITO/HEMOGLOBINA MÉDIA EM DIFERENTES FASES

\begin{tabular}{|c|c|c|c|c|c|c|}
\hline & \multicolumn{2}{|c|}{ Pré- } & \multicolumn{2}{|c|}{ P.O.I. } & \multicolumn{2}{|c|}{$5^{\circ}$ P.O.I. } \\
\hline $\begin{array}{l}\text { Grupo A } \\
\text { Grupo B }\end{array}$ & $\begin{array}{l}43 \\
41,8\end{array}$ & $\begin{array}{l}14,4 \\
13,9\end{array}$ & $\begin{array}{l}41,5 \\
35,9\end{array}$ & $\begin{array}{l}13,5 \\
11,7\end{array}$ & $\begin{array}{l}36,2 \\
34,5\end{array}$ & $\begin{array}{l}11,8 \\
11,4\end{array}$ \\
\hline
\end{tabular}

HTC: hematócrito

$\mathrm{Hgb}$ : hemoglobina

O número de Grupo $A$, que não necessitou sangue homólogo durante todo o período de internação, foi o dobro $(5,7 \%)$ em relação ao do Grupo B $(2,8 \%)$. A maioria dos pacientes do Grupo A $(51,4 \%)$ utilizou no máximo duas unidades de sangue homólogo, enquanto que a maioria dos pacientes do Grupo B $(78,6 \%)$ utilizou entre 3 ou mais de 5 unidades de sangue homólogo (Tabela 6).

TABELA 6

NÚMERO DE UNIDADES DE SANGUE/DERIVADOS HOMÓLOGOS UTILIZADOS NOS PACIENTES DURANTE TODA A INTERNAÇĀO

\begin{tabular}{lrr}
\hline N. DE UNIDADES & GRUPO A & \multicolumn{1}{c}{ GRUPO B } \\
\hline Zero & $4(5,7 \%)$ & $2(2,8 \%)$ \\
1 a 2 unidades & $32(45,7 \%)$ & $13(18,6 \%)$ \\
3 a 5 unidades & $24(34,2 \%)$ & $38(54,3 \%)$ \\
$>5$ unidades & $10(14,2 \%)$ & $17(24,3 \%)$ \\
\hline
\end{tabular}

O tempo médio total das operaçōes, perfusão e anóxia (nos casos onde houve CEC), foi semeIhante, sendo que no Grupo A foi 5,6 horas, 99 minutos e 56 segundos, enquanto que, no Grupo $B$, foi de 6 horas, 90 minutos e 58 segundos, respectivamente.

Os casos de óbito no Grupo A foram em número de $10(14,2 \%)$, sendo que no Grupo B de 8 $(11,4 \%)$.

Em nenhum dos casos do Grupo A houve com- 
VIEIRA, S. D.; SANTOS, M.; ROSALES, T.; SOUZA, L. C. B.; DINKHUYSEN, J. J.; CHACCUR, P.; ABDULMASSIH NETO, C.; PAVANELLO, R.; JATENE, A. D. - Autotransfusāo intra-operatória em cirurgia cardíaca: estudo comparativo de 140 casos. Rev. Bras. Cir. Cardiovasc., 7(4):287-292, 1992.

plicação infecciosa aguda, hematológica ou clínica, que pudesse ser relacionada ao uso da recuperação celular intra-operatória ${ }^{10}$

\section{COMENTÁRIOS}

Com a crescente conscientização das vantagens da autotransfusão ? vários grupos e organizaçōes ${ }^{5}$ têm reforçado a necessidade do aumento do uso de sangue autólogo.

$\mathrm{Na}$ investigação de um procedimento especial na recuperação sangüínea, grupos homogêneos de pacientes submetidos a cirurgia cardíaca foram comparados (Tabelas 1 e 2).

Este estudo demonstrou que o uso da autotransfusāo intra-operatória em cirurgia cardíaca é um procedimento eficiente eficiente no aumento da utilizaçāo de sangue autólogo ?

Os níveis de hemócrito e hemoglobina observados nos exames pré-autotransfusão intra-operatória e pós-autotransfusāo intra-operatória (Tabela 3), e principalmente a diminuição do uso de sangue homólogo no pós-operatório reafirmam a hipótese de que a técnica não induz a significativa coagulopatia clínica ${ }^{4}$. Apesar da ausência de fatores de coagulação e albumina nos glóbulos autólogos lavados, o uso de plasma fresco congelado, plaquetas e crioprecitado não foi significamente diferente nos grupos comparados (Tabela 4).

A colheita de uma unidade de sangue autólogo nos pacientes hemodinamicamente estáveis na sala cirúrgica, antes da heparinização do paciente, atua inicialmente no processo de hemodiluiçăo normovolêmica aguda ". A sua reinfusão após a saída de CEC promove uma acentuada mnelhora nas condiçōes hemostáticas do paciente, devido, principalmente, ao plasma fresco, aos fatores de coagulação e às plaquetas, que não foram heparinizadas e nem sofreram atuação da bomba de perfusão.

Concluímos, portanto, que a combinação de diferentes métodos de recuperação sangüinea leva a uma significativa reduçāo de sangue e que a autotransfusão intra-operatória em cirurgia cardíaca é um procedimento seguro e eficaz ${ }^{16}$ reduzindo em aproximadamente $50 \%$ a utilizaçāo de sangue homólogo ${ }^{3}, \mathrm{com}$ possíveis reaçōes adversas e, principalmente, o risco de transmissão de doenças infectocontagiosas.

\section{RBCCV 44205-192}

VIEIRA, S. D.; SANTOS, M.; ROSALES, T.; SOUZA, L. C. B.; DINKHUYSEN, J. J.; CHACCUR, P. ABDULMASSIH NETO, C.; PAVANELLO, R.; JATENE, A. D. - Intraoperative autotransfusion in heart surgery: comparative study of 140 cases. Rev. Bras. Cir. Cardiovasc., 7(4):287-292, 1992.

ABSTRACT: An intraoperative autotransfusion was planned in order to decrease or to avoid transfusion of blood in severe surgical cases. It was done a comparative study in 140 heart surgeries; 70 cases (Group A) were submitted to heart surgery making use of Cell-Saver and 70 without the use of it. The majority of the cases have had a previous surgery; $77.1 \%$ of the cases in Group A and $74.2 \%$ in Group B. Besides this similarity other likeness included age, sex, kind of surgery, clinical conditions and laboratory data concerning coagulation, erythrocyte count and blood biochemistry. The averaged homologous blood volume intraoperative transfused was $628 \mathrm{ml}$ in Group A and $1271 \mathrm{ml}$ in Group B, but it was $479 \mathrm{ml}$ in Group A and $1095 \mathrm{ml}$ in Group B after surgery. The intraoperative blood lost was $380 \mathrm{ml}$ in Group B. During the hospitalization time the percentage of cases that did not receive blood was $5.7 \%$ in Group A and 2,8\% in Group B. The average amount of units transfused was 2 in Group A and 3 ro 5 or higher in Group B. The study pointed out that intraoperative autologous transfusion using Cell Saver is a safety and efficient procedure. The transfusion of homologous blood decreased in $50 \%$ as well as the risk of infection disease to be transmited.

DESCRIPTORS: blood, autotransfusion in heart surgery.

\section{REFERÊNCIAS BIBLIOGRÁFICAS}

1 AUTOLOGOUS Blood transfusion: current issues. Arlington, Virgínea, American Association of Blood Banks, 1988. 260 p. E.; FABIANI, N. J., ABRY, B.; CARPENTIER, A. Autotransfusion en chirurgie cardiaque: interet du lavage globulaire dans les interventions à haut ris- 
VIEIRA, S. D.; SANTOS, M.; ROSALES, T.; SOUZA, L. C. B.; DINKHUYSEN, J. J.; CHACCUR, P.; ABDULMASSHH NETO, C.; PAVANELLO, R.; JATENE, A. D. - Autotransfusão intra-operatória em cirurgia cardíaca: estudo comparativo de 140 casos. Rev. Bras. Cir. Cardiovasc., 7(4):287-292, 1992.

que hemorragique. Ann. Chir. Thorac. Cardiovasc., 41: $421-425,1987$.

DIETRICH, W.; BARANKAY, A.; DILTHEY, G.; MITTO, H. P.; RICHTER, J. A. - Reduction of blood utilization during myocardial revascularization. J. Thorac. Cardiovasc. Surg., 97: 213-219, 1989.

GIORDANO, J. D.; GOLDMAN, D. S.; MAMMANA, R. B.; MARCO, J. D.; - Intraoperative autotransfusion in cardiac operations. J. Thorac. Cardiovasc. Surg., 96: $382-386,1988$.

GUIDELINES for perioperative autologous transfusion. Arlington, Virgínia, American Association of Blood Banks, 1991. 177 p.

6 MORAN, J. M.; BABKA, R.; SILBERMAN, S. - Immediate centrigugation of oxygenator contents after cardiopulmonary by pass. J. Thorac. Cardiovasc. Surg., 76: $510-517,1978$.

SANDLER, S. G. \& SILVERGLEID, A. J. (eds.) - Autologous transfusions. Arlington, Virginia, American Association of Blood Banks, 1983.

SCHAFF, H. V.; HAWER, J. M.; BELL, V. R. - Autotransfusion of shed mediastinal blood after cardiac surgery: a prospective study. J. Thorac. Cardiovasc. Surg., 75: 632-641, 1978.

SCHAFF, H. V.; HAWER, J. M.; GARDER, T. J.; Routine use of autotransfusion following cardiac surgery: experience in 700 patients. Ann. Thorac. Surg., 27: 493-499, 1979.

TOY, P. T.; STRAUSS, R. G.; STEHLING, L. C.; SEAKS, R.; PRICE, T. H.; ROSSI, E. C. - Pre deposited autologous blood for elective surgery: a National Multicenter Study. New Engl. J. Med., 316: 517-520, 1987.

TRANSFUSION Associated AIDS: a cause for concern. New Engl. J. Med., 301: 115-116, 1984. (Editorial).

ULMAS, J. \& O'NEILL, T. P. - Heparin removal in an autotransfusior device. Transfusion, 21: 70-73, 1981.

WENIGER, J. \& SHANNAHAN, R. - Reduction of blood requirements In cardiac surgery. Thorac. Cardiovasc. Surg., 30:142-146, 1982.

WINTON, T. L.; CHARRETTE, E. J. P.; ERNO, T. A. The cell saver during cardiac surgery: does it save? An. Thorac. Surg., 33: 379-381, 1982.

\section{Discussão}

\section{DR. OTONI MOREIRA GOMES Belo Horizonte, MG}

Em nome do Serviço do Coração do Hospital São Francisco de Assis de Belo Horizonte, agradecemos à Comissão Organizadora do Congresso - privilégio desta participação, enaltecemos a grande importância prática da experiência relatada e parabenizamos a Equipe de Cirurgia Cardíaca do Hospital do Coração de São Paulo, pela excelência dos resultados obtidos no tratamento de patologias de alto risco, como se depreende da casuística estudada. Nossa interpretação do presente trabalho oferece oportunidade para uma discussāo muito prdutiva. Entendemos que não existe homogeneidade que permita comparação fidedigna entre os dois grupos, o que é quase impossível no âmbito clínico, porque o fato de dois pacientes de mesmo sexo e idade serem reoperados não os torna semeIhantes quanto à possibilidade de sangramento. A hemorragia nas reoperaçōes depende da localização, intensidade e extensão das aderências teciduais e da habilidade e tática de cada cirugiāo em desfazêlas. A análise numérica da casuística favorece a conclusāo de que no grupo controle foram mais freqüentes as cirurgias potencialmente mais hemorrágicas. Também existe uma descriçāo de casos operados sem circulação extracorpórea e que, não sendo definidos quanto ao grupo alocado, parecem estar no Grupo A, ou seja, de autotransfusāo. A Tabela 3 mostra que no grupo de autotransfusão o volume aspirado no campo variou de 50 a $4.473 \mathrm{ml}$, com média de $513 \mathrm{ml}$. Năo existe referência à intensidade de sangramento do grupo controle e, ademais, um desvio padrão com valores diferenciando da média em até 8 vezes $(800 \%)$ é impróprio para qualquer consideração estatística. Outro fator que distancia da homogeneidade os dois grupos considerados é o período de estudo: todos os pacientes do Grupo A (autotransfusāo) foram operados entre abril e outubro de 1991, ou seja, num interlúdio de sete meses, compativel com a atuaçăo praticamente de uma mesma equipe. Já os pacientes do grupo controle (B) foram operados entre novembro de 1988 e dezembro de 1991 , ou seja, num espaço de três anos, e todos sabemos o que acontece com a estabilidade da cirurgia a cada nova safra de residentes no campo operatório. Se fosse possivel uma conclusāo científica, ela seria exatamente o oposto daquela descrita. Os números provam que a recuperação celular cell-saver prejudicou significantemente a hemostasia dos pacientes, tendo evoluído muito melhor o grupo controle, no qual foi, inclusive, menor a mortalidade. Uma revisão atenciosa da Tabela 4 confirma nosso entendimento, pois observamos que os pacientes com autotransfusão de sangue lavado necessitam cinco vezes mais de 
VIEIRA, S. D.; SANTOS, M.; ROSALES, T.; SOUZA, L. C. B.; DINKHUYSEN, J. J.; CHACCUR, P.; ABDULMASSIH NETO, C.; PAVANELLO, R.; JATENE, A. D. - Autotransfusão intra-operatória em cirurgia cardíaca: estudo comparativo de 140 casos. Rev. Bras. Cir. Cardiovasc., 7(4):287-292, 1992.

transfusão de plaquetes e criofatores do que o grupo controle. Sabemos, ainda, que o risco de contaminaçāo, sensibilização e embolia na transfusāo de concentrados de plaquetas năo é menor do que na do sangue homólogo. Dr. Vieira, nāo podemos deixar de lamentar o fato de que, em toda sua bibliografia, nảo conste nenhum dos excelentes trabalhos brasileiros sobre autotransfusão em cirurgia cardíaca, alguns com recursos originais e importante contribuiçāo tecnológica. Finalizando, gostaríamos de ressaltar o fato de que, apesar de todo empenho para evitar a transfusāo de sangue, ela foi necessária em $95 \%$ dos casos, o que contra-indica formalmente cirurgia de reoperação cardíaca em pacientes Testemunhas de Jeová. O senhor já vivencicou alguma vez este problema? Muito obrigado.

\section{DR. VIEIRA \\ (Encerrando)}

Os estudos comparativos, utilizados em trabaIhos científicos, consistem numa técnica utilizada mundialmente há várias décadas, justificando, portanto, a realização do trabalho, visto que os grupos em questāo são extremamente semelhantes entre si. A introduçào dessa técnica no Hospital do Coraçăo, a partir de abril de 1991, se orientou na experiência de outros Serviços, e de vasta literatura científica, pois, na América, esse mesmo procedimento já é realizado há 19 anos, com excelentes benefícios aos pacientes. Por isso, desde entāo, todos os pacientes graves, ou seja, aqueles que poderiam se beneficiar desse procedimento, foram incluídos nesse programa, nāo havendo, portanto, preocupaçāo quanto à mesma periodicidade de estudo entre os grupos e muito menos à "nova safra de residentes" no campo operatório, pois é inadmissível pensar que, a cada nova safra de residentes, haja um prejuízo ao Serviço e, principalmente, aos pacientes. Conforme podemos observar na Tabela 6 , a maioria dos pacientes que utilizaram a cell-saver $(51,4 \%)$ necessitaram no máximo de 2 unidades de sangue e/ou derivados homólogos (sendo incluídos aqui, plaquetas, crioprecipitado etc), enquanto que a maioria dos pacientes do Grupo controle $(78,6 \%)$ utilizou entre 3 a 5 unidades, comprovando que essa técnica é um procedimento seguro e eficaz na reduçāo do uso de sangue homólogo, e recomendada pelos pacientes Testemunhas de Jeová. 